\title{
State of the Art on Prediction of Concrete Pumping
}

\author{
Seung Hee Kwon"), Kyong Pil Jang ${ }^{1)}$, Jae Hong Kim²),*, and Surendra P. Shah ${ }^{3)}$
}

(Received March 22, 2016, Accepted May 10, 2016, Published online June 16, 2016)

\begin{abstract}
Large scale constructions needs to estimate a possibility for pumping concrete. In this paper, the state of the art on prediction of concrete pumping including analytical and experimental works is presented. The existing methods to measure the rheological properties of slip layer (or called lubricating layer) are first introduced. Second, based on the rheological properties of slip layer and parent concrete, models to predict concrete pumping (flow rate, pumping pressure, and pumpable distance) are explained. Third, influencing factors on concrete pumping are discussed with the test results of various concrete mixes. Finally, future need for research on concrete pumping is suggested.
\end{abstract}

Keywords: pumping, slip layer, prediction, rheology, tribometer.

\section{Introduction}

Concrete pumping method was first introduced in the United States during early 1930 (Kaplan et al. 2005), and this method is now commonly used in construction sites. The merit of concrete pumping is the continuous casting of concrete, which reduces the casting time and consequently the cost of construction. Also, it is effective where the use of large equipment is restricted in a site. In many construction sites, the use of pumping is determined based on the workers' experience and on qualitative assessment of concrete pumpability based on the slump test or the slump flow test. However, for major construction sites requiring long-distance transport of concrete, such as high-rise buildings, long-span bridges, longdistance tunnels and others, priori prediction of concrete pumpability growing in importance. A quantitative prediction for pumping pressure, flow rate and pumpable distance, prior to pumping, provides valuable information for establishing the overall construction plan including equipment selection and all processes related to concrete placement.

A quantitative estimation of concrete pumping needs understanding of the mechanism of concrete flow inside a pumping pipe. Most research results (Kaplan et al. 2005; Tattersall and Banfill 1983; Alekseev 1952; Ede 1957;

\footnotetext{
${ }^{1)}$ Department of Civil and Environmental Engineering, Myongii University, Yongin, Korea.

${ }^{2)}$ School of Urban and Environmental Engineering, Ulsan National Institute of Science and Technology, Ulsan, Korea.

*Corresponding Author; E-mail: jaekim@unist.ac.kr

${ }^{3)}$ Department of Civil and Environmental Engineering,

Northwestern University, Evanston, IL, USA.
}

Copyright $($ The Author(s) 2016. This article is published with open access at Springerlink.com
Weber 1968; Morinaga 1973; Browne and Bamforth 1977; Sakuta et al. 1989; Jacobsen et al. 2009; Jo et al. 2012; Choi et al. 2013; Kwon et al. 2013a, b; Mechtcherine et al. 2014; Ngo et al. 2010; Jacobsen et al. 2008; Choi 2013; Choi et al. 2013,2014 ) reports the critical influence of the slip layer (or sometimes called lubricating layer) formed between concrete and the inner wall of the pipe. The relatively thin slip layer has a very low viscosity compared to the bulk concrete (Jacobsen et al. 2009; Jo et al. 2012; Choi et al. 2013; Kwon et al. 2013a, b; Choi 2013; Choi et al. 2013, 2014). The existence of the slip layer was first recognized by Alekseev (1952). The bleed water of concrete, the wall effect on the pipe, and shear-induced particle migration (SIPM) reportedly contributes to formation of the slip layer (Ngo et al. 2010; Choi 2013; Choi et al. 2013, 2014; Koehler et al. 2006; Wallevik 2008; Phillips et al. 1992; Kaplan et al. 2005). Concrete pumping performance is closely related to the rheological properties of pumped (bulk) concrete and that of the slip layer. Various researches on the pumping (Kaplan et al. 2005; Choi et al. 2013; Kwon et al. 2013a, b; Mechtcherine et al. 2014; Choi 2013; Choi et al. 2014) indicate that a lower viscosity of the slip layer is beneficial for pumping performance. Inversely, the pumping performance can be manipulated by controlling the rheological properties of the slip layer.

Four different cases have been reported regarding the influencing factors on the friction force in the slip layer: (1) The frictional force in the slip layer is constant regardless of the pumping pressure or velocity (Sakuta et al. 1989; Lipovetski 1963); (2) The frictional force in the slip layer is linearly proportional to the flow rate of pumping (Weber 1968; Morinaga 1973; Browne and Bamforth 1977); (3) The frictional force in the slip layer increases linearly proportional to the normal stress applied on the piping walls (Alekseev 1952; Ede 1957; Chalimo et al.1989); (4) The frictional force in the slip layer is affected by both the flow 
rate and the normal stress applied on the piping walls (Tanigawa et al. 1991). Recent studies based on mockup pumping tests (Kaplan et al. 2005; Kwon et al. 2013a, b; Mechtcherine et al. 2014; Choi 2013; Choi et al. 2014; Rio et al. 2005) support the 2 nd case.

Kaplan et al. (2005) modified the BTRheom (De Larrard et al. 1997) concrete rheometer to develop an equipment called tribometer, which is capable of measuring the rheological properties of the slip layer. Subsequent to Kaplan's development of the tribometer, other researchers have developed models and test equipment: for examples, Chapdelaine et al. (2007), Ngo et al. (2010), Kwon et al. (2013a, 2013b), Feys et al. (2014), and Kim et al. (2014).

The objective of this paper is to summarize the pumping prediction technologies developed as of the present day. First and foremost, methods for measuring the rheological properties of the slip layer are introduced. Secondly, a fundamental model of pumping prediction using the rheological properties of the slip layer are described. Thirdly, the factors influencing the pumpability of concrete are analyzed. Finally, future research topics on concrete pumping are discussed. The state-of-the-art study on concrete pumping would be useful knowledge for researchers and construction industry.

\section{Slip Layer During the Concrete Pumping}

\subsection{Thickness of the Slip Layer}

The performance of concrete pumping is governed by the characteristics of the slip layer formed between the piping surface and the concrete. Ngo et al. (2010) used various concrete mixtures according to the grading of coarse and fine aggregates and the cement type. The pumping test results supported that the constituents composing the slip layer are water, cement, and fine sand smaller than $0.25 \mathrm{~mm}$. The slip layer thickness is proportional to the volume of the cement paste, the water-to-cement ratio, and the dosage of superplasticizer. The slip layer thickness also decreases with a higher amount of fine sand. The length and diameter of pipeline are also considered to change the thickness of the slip layer.

In spite of the variation of the slip layer thickness, it is generally accepted as roughly $2 \mathrm{~mm}$ thick (Jo et al. 2012; Choi 2013). A flow simulation conducted by Jo et al. (2012) and Choi (2013; Choi et al. 2013a, 2013b) showed that the thickness of the slip layer slightly depends on the length of the pipe, concrete mixture, and the piping diameter. However, the test results showed its variation is not large during the pumping process (Choi 2013). The velocity of concrete pumping is developed more than $90 \%$ within the $2 \mathrm{~mm}$ thick slip layer. Choi (2013) and Choi et al. (2014) installed a transparent pipe for the $170 \mathrm{~m}$ full-scale pumping test to take a direct measurement of the velocity distribution inside the pipe using an ultrasonic velocity profiler (UVP) (Metflow 2002). The thickness of the slip layer, deduced from the velocity distribution, varies slightly depending on the mixproportion of concrete even though its approximation could be still said to $2 \mathrm{~mm}$.

\subsection{Characterization of the Slip Layer Using a Tribometer}

The first concrete tribometer developed by Kaplan et al. (2005) is comprised of a concrete container, a rubber seal installed on the bottom of the container to prevent concrete leakage, cylindrical rotating axis, and a motor connected through the cylindrical rotating axis. The equipment rotates the center cylinder immersed in concrete at a fixed rotation speed, and it measures the corresponding torque to calculate the rheological properties of the slip layer. Figure 1 illustrates the original concept of the tribometer and the process of pumping prediction using the tribometer. First, the rotation speed of the cylindrical rotating axis is set to five different speeds of $0.20,0.55,0.90$, $1.25,1.60 \mathrm{rps}$ (revolution per second) to measure the corresponding torque. The flow layer formed between the cylinder surface and the concrete is considered the slip layer. The rheological property of the slip layer can be calculated based on the relationship between the torque and the angular velocity (converted from the rotating speed). The rheological property of the slip layer measured through the tribometer is used to calculate the pumping pressure and the flow rate. The pumping pressure calculation of the Kaplan's model is shown by

$$
P=\frac{2 L}{R}\left(\frac{Q}{3600 \pi R^{2} k} \eta^{t}+\tau_{0 i}^{t}\right)
$$

where $P$ is the pumping pressure $(\mathrm{Pa}), Q$ is the flow rate $\left(\mathrm{m}^{3} /\right.$ $\mathrm{h}), L$ is the pipe length (m), $R$ is the pipe diameter $(\mathrm{m}), k$ is the parameter optimally fitting the slope or the linearity between the torque and the angular velocity ( $\mathrm{N} \mathrm{m} \mathrm{s} / \mathrm{rad}), \tau_{0 i}^{t}$ is the yield stress of slip-layer $(\mathrm{Pa})$, and $\eta^{t}$ is the interface viscous constant $(\mathrm{Pa} \mathrm{s} / \mathrm{m})$. The pumping prediction of the model was verified through 180 and $230 \mathrm{~m}$ pipe length fullscale pumping tests (Kaplan et al. 2005).

Tattersall and Banfill (1983) and Chapdelaine (2007) refined the rubber seal installed on the floor of the container to prevent concrete leakage. The rubber seal in the original Kaplan's tribometer causes additional torque at the point where the cylinder meets the rubber seal at the bottom which affects the torque measurement. Even small error on the measured torque can give unreliable determination on the rheological property of the slip layer because its viscosity is relatively small compared to that of concrete. Its verification was done by pumping tests at a laboratory level: $15 \mathrm{~m}$-long pumping circuit, where Kaplan's model for predicting the pumping pressure was used. However, its application on full-scale or in-filed pumping test has yet been reported.

Figure 2 illustrates the shape and dimension of the Chapdelaine's tribometer. Chapdelaine's tribometer, developed with the original Tattersall Mk-III rheometer (Tattersall and Banfill 1983), uses a hollow internal cylinder, and it has ribs inside to prevent rotation of the concrete inside the cylinder. However, the use of the hollow cylinder causes error on developing the slip layer and measuring the frictional force. In addition, concrete with very low fluidity could form a space between the rotating cylinder and the concrete, which could cause difficulties for accurately measuring the rheological properties of the slip layer. 

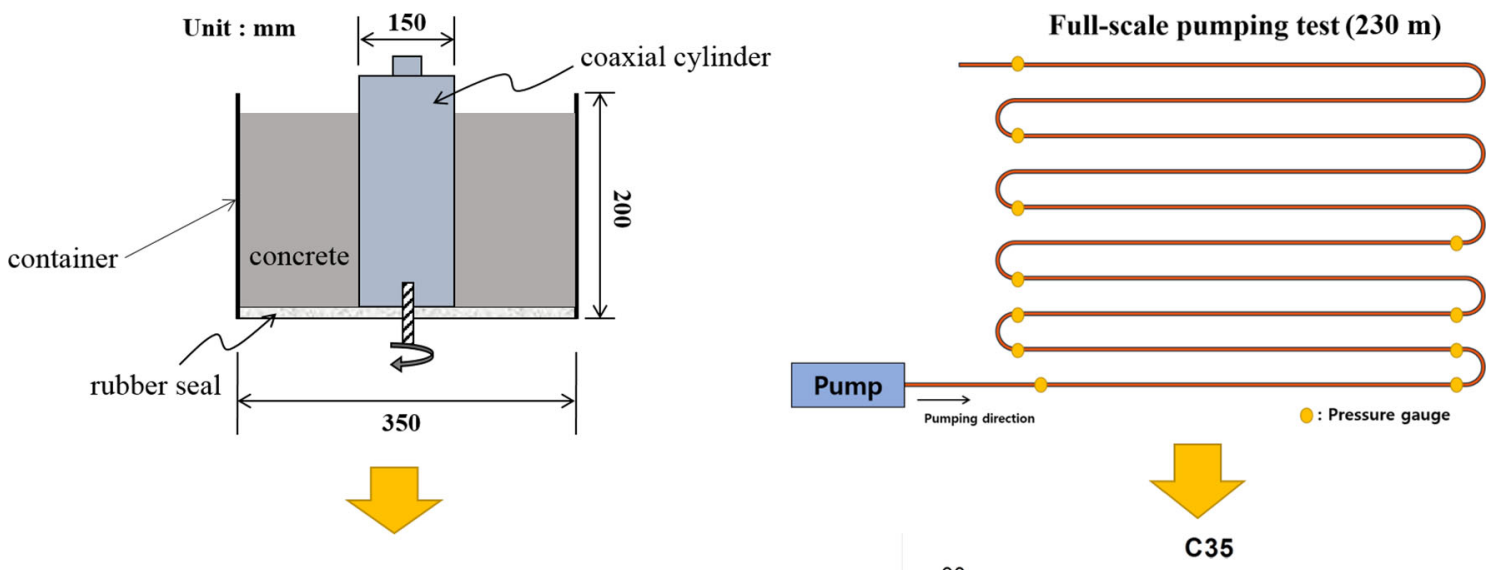

$$
\begin{gathered}
\tau_{0 i}^{t}=\frac{\Gamma_{0}}{2 \pi R^{2} h} \quad \eta^{t}=\frac{k}{2 \pi R^{3} h} \\
P=\frac{2 L}{R}\left(\frac{Q}{3600 \pi R^{2} k} \eta^{t}+\tau_{0 i}^{t}\right)
\end{gathered}
$$

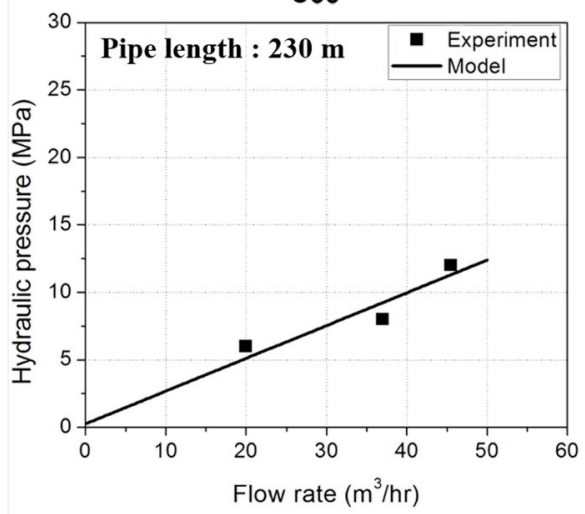

Fig. 1 Rheological property evaluation of the slip layer and pumping estimation method based on Kaplan et al. (2005).

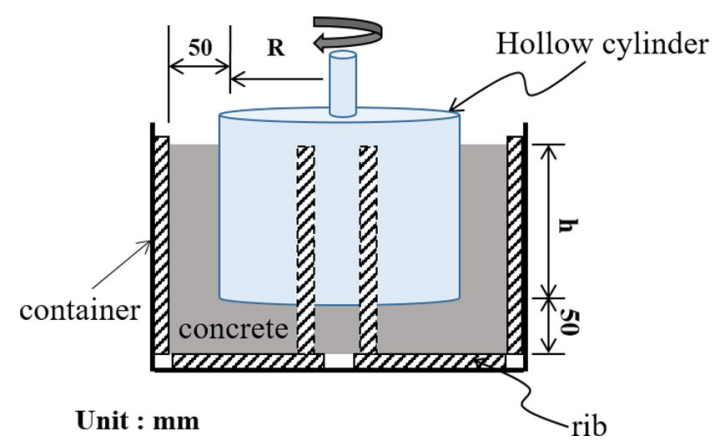

Fig. 2 Schematic description of Chapdelaine's tribometer (Chapdelaine 2007).

Ngo et al. (2010) returned to the original form of tribometer as illustrated in Fig. 3, where it includes the rotating cylinder on the flat bottom surface of the container. Two separate measurements are taken at different depths of concrete filled in the container. This was done to eliminate the friction measurement value in the bottom surface of the cylinder. The first measurement is taken by filling the cylinder with concrete to the bottom of the rotating cylinder, and the second measurement is done by full filling. The rheological property of the slip layer can be calculated by using the difference between the first and second measurements. However, its verification through real-scale pumping test was not reported in the original proposition.

Kwon et al. (2013a, 2013b) developed a new tribometer to precisely measure the rheological property of the slip layer in conjunction with a pumping prediction algorithm. The
Kwon's tribometer was proposed by modifying the ICAR Rheometer, a commercially available rheometer to measure the rheological property of concrete. It has a vane with a rotating diameter of $130 \mathrm{~mm}$ and a height of $240 \mathrm{~mm}$. Figure 4 illustrates the method of measuring the rheological properties of the slip layer using the Kwon's tribometer and the process of pumping prediction. Taking the separate measurements at two different depth of concrete, similar to the Ngo's procedure, allows to eliminate the shear rate concentration on the bottom surface and edges of the rotating cylinder. Numerous test results on various concrete mixtures provide the optimized depths of concrete, $h_{1}$ and $h_{2}$ to be tested. These are 200 and $300 \mathrm{~mm}$. In addition, a precise calculation on the rheological property of the slip layer could be achieved by assuming the thickness of the slip layer. Note that the model using the aforementioned three tribometers does not consider the slip layer thickness for the calculation. Figure 5 illustrates the velocity profile inside the pipe during pumping, and three layers are formed: slip-layer zone, shearing zone in concrete, and plug flow zone in concrete (Kwon et al. 2013b). Kwon et al. (2013b) applied the assumption of 2-mm thick slip layer on an SIPM model, and then calculated the distribution of the rheological property of the slip layer. The flow rate by integrating the velocity distribution inside the pipe during pumping is finally given by

$$
\begin{aligned}
Q= & \int_{R_{L}}^{R_{P}} 2 \pi r U_{S} d r+\int_{R_{G}}^{R_{L}} 2 \pi r U_{P 1} d r+\int_{0}^{R_{G}} 2 \pi r U_{P 2} d r \\
= & 3600 \frac{\pi}{24 \mu_{S} \mu_{P}}\left[3 \mu_{P} \Delta P\left(R_{P}^{4}-R_{L}^{4}\right)-8 \tau_{S, 0} \mu_{P}\left(R_{P}^{3}-R_{L}^{3}\right),\right. \\
& \left.+3 \mu_{S} \Delta P\left(R_{L}^{4}-R_{G}^{4}\right)-8 \tau_{P, 0} \mu_{S}\left(R_{L}^{3}-R_{G}^{3}\right)\right]
\end{aligned}
$$




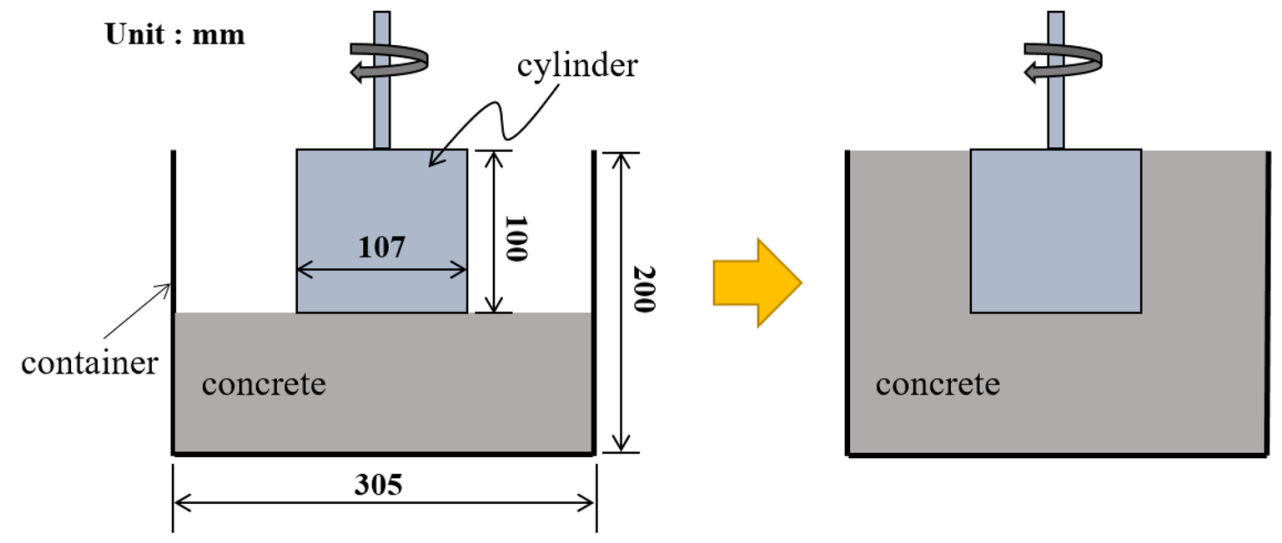

Fig. 3 Shape and measurement methods of Ngo's tribometer (Ngo et al. 2010).
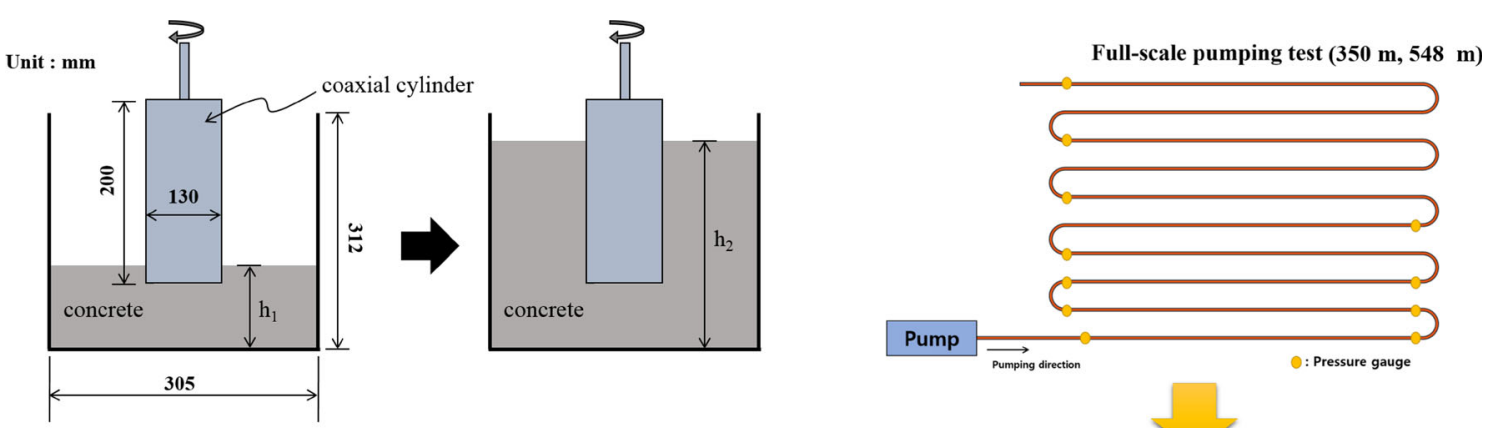

$$
\begin{gathered}
\mu_{s}=\frac{k}{4 \pi h}\left[\frac{1}{R_{c}^{2}}-\frac{1}{R_{s}^{2}}\right] \quad \tau_{s, 0}=\frac{\Gamma_{0}}{2 \pi h R_{c}^{2}} \\
Q=3600 \frac{\pi}{24 \mu_{S} \mu_{P}}\left[3 \mu_{P} \Delta P\left(R_{P}^{4}-R_{L}^{4}\right)-8 \tau_{S, 0} \mu_{P}\left(R_{P}^{3}-R_{L}^{3}\right)\right. \\
\left.+3 \mu_{S} \Delta P\left(R_{L}^{4}-R_{G}^{4}\right)-8 \tau_{P, 0} \mu_{S}\left(R_{L}^{3}-R_{G}^{3}\right)\right]
\end{gathered}
$$

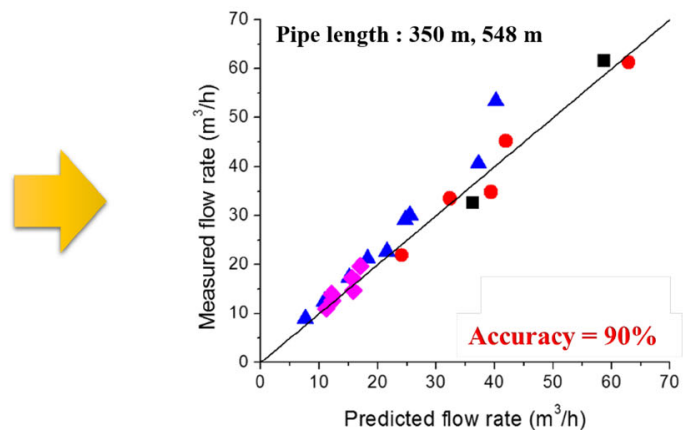

Fig. 4 Pumping estimation method based on Kwon et al. (2013a, 2013b).

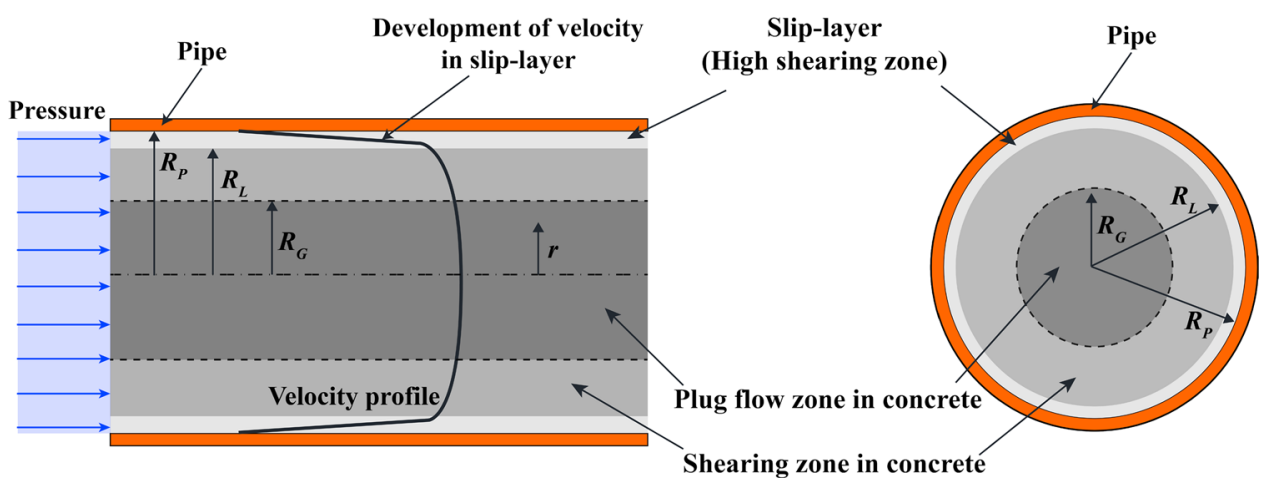

Fig. 5 Velocity profile of pumped concrete in pipe (Kwon et al. 2013).

where $Q$ is the flow rate $\left(\mathrm{m}^{3} / \mathrm{h}\right), r$ is an arbitrary position in radial direction, $U_{S}$ is the velocity profile within the sliplayer, $U_{P 1}$ is the velocity profile within the shearing zone, $U_{P 2}$ is the velocity in the plug flow zone, $R_{P}$ is the radius of pipe, $R_{L}$ is the distance from the center of the pipe to the sliplayer, $R_{G}$ is the radius at which the shear rate starts, $\Delta P$ is the pressure per unit length $(\mathrm{Pa} / \mathrm{m}), \tau_{P, 0}$ and $\mu_{P}$ are the yield stress $(\mathrm{Pa})$ and the viscosity $(\mathrm{Pa} \mathrm{s})$ of the concrete, 
respectively. The difference between $R_{P}$ and $R_{L}$ is the slip layer thickness. Verification of the pumping prediction method was accomplished through 350 and $548 \mathrm{~m}$ long fullscale pumping tests.

Choi (2013) proposed that the rheological property of the slip layer of pumped concrete can be possibly measured with the mortar acquired through wet screening of pumped concrete (using a $5 \mathrm{~mm}$ sieve). Figure 6 illustrates the process of rheological property assessment of the slip layer and pumping prediction proposed by Choi (2013). Brookfield DV-II viscometer (Brookfield Engineering Laboratories Inc. 2006) was used to measure the rheological property of the wet-screened mortar. A rotating cylinder of $8 \mathrm{~mm}$ diameter and $60 \mathrm{~mm}$ height was used in a container having a diameter of $35 \mathrm{~mm}$. The volume of mortar sample was $0.5 \mathrm{~L}$. The range of rotating speed was set in between 0.4 and 4.2 rps. The pumping prediction was done by using the model proposed by Kwon et al. (2013).

It should be noted that it is inconvenient to perform wet screening for every test, and the quality of the wet-screened mortar may be inconsistent. The assumption that the mortar has the same property of the slip layer has not been strictly verified. As mentioned previously, Ngo et al. (2010) presumed that the suspension of particles which are less than $0.25 \mathrm{~mm}$ composes the slip layer of the pumped concrete. Figure 7 compares the results of the pumping prediction based on the propositions by Kwon et al. (2013), Choi (2013) and Choi et al. (2014), where pumped concrete was assumed the same for all cases. The thickness of the slip layers was a control parameter showing variation in between 1 and $3 \mathrm{~mm}$ even though its average was still $2 \mathrm{~mm}$. Both propositions used the same method for the pumping

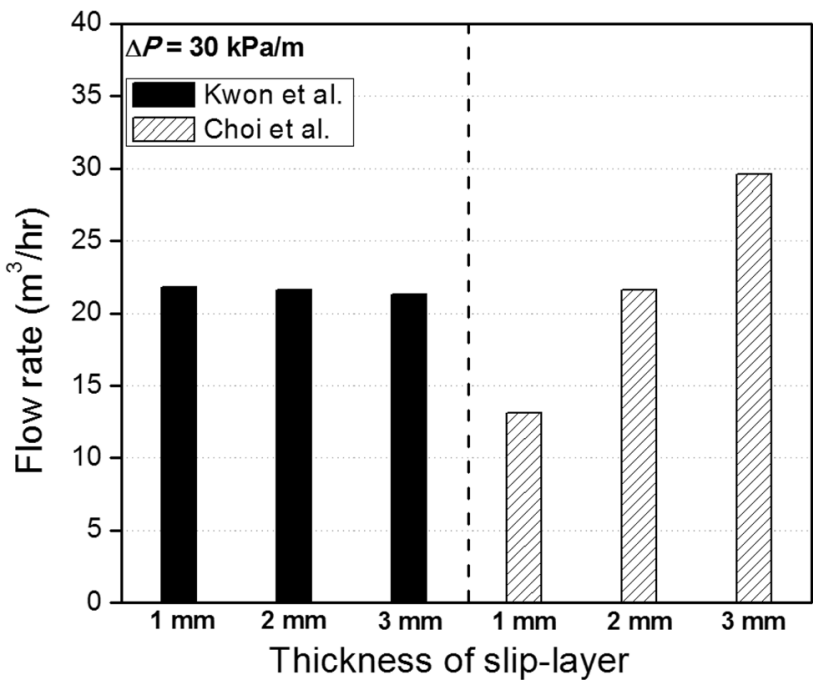

Fig. 7 Results of calculated flow rate according to the thickness of slip-layer.

prediction, and then the results depend on each measuring method of the rheological property of the slip layer. From Fig. 7, it can be seen that the slip layer measurement method proposed by Kwon et al. (2013) is more appropriate compared to the method proposed by Choi (2013) and Choi et al. (2014).

Feys et al. (2014) modified Tattersall Mk-III Tattersall and Banfill (1983) to develop a tribometer. Figure 8 illustrates the shape and size of Feys' tribometer. For convenience purposes, Feys et al. (2014) designed the end part of the inner cylinder in a conical shape. This tribometer was used to assess the rheological properties of the slip layer of highly-workable concrete and SCC (self-consolidating
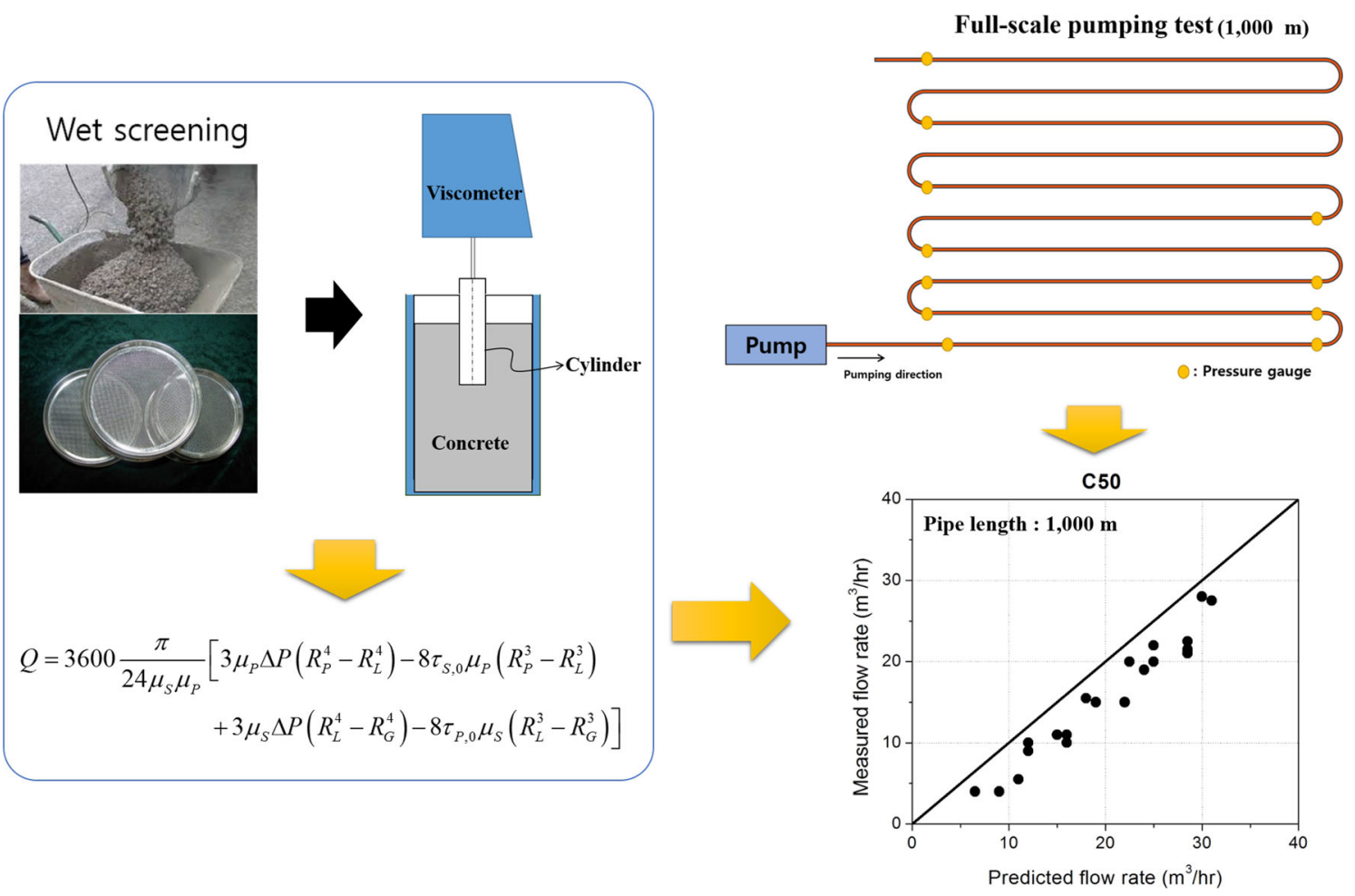

Fig. 6 Pumping estimation method based on Choi (2013). 


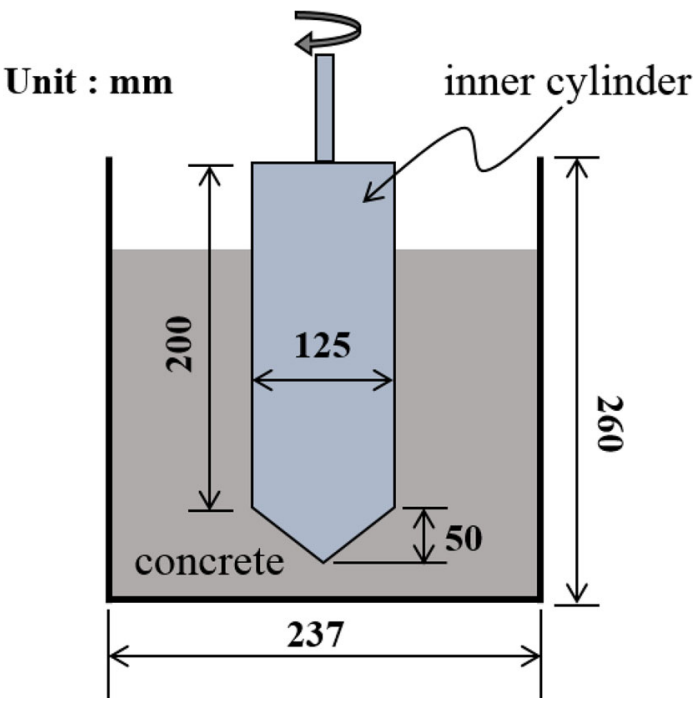

Fig. 8 Schematic description of Feys' tribometer (Feys et al. 2014).

concrete). The measured value of the rheological property of the slip layer was applied to the pumping prediction model developed by Kaplan et al. (2005) for pumping prediction (Feys et al. 2015). Its verification was performed through a $30 \mathrm{~m}$ pipeline pumping test, where 125 or $100 \mathrm{~mm}$-diameters of pipe were used. The comparison of the two differentsized pipe showed that $20 \%$ reduction of pipe diameter caused the pumping pressure to double (Feys et al. 2016). However, similar to Chapdelaine's tribometer and Ngo's tribometer, verifications through a full-scale or in-field pumping test have not yet been performed.

\subsection{Characterization of the Slip Layer Using a Pumping Pipe}

Another method to measure the characteristics of the slip layer is done by using a pipe segment similar to the actual pumping pipe. Mechtcherine et al. (2014) developed an equipment called Sliding Pipe Rheometer (abbreviated by Sliper) to assess the rheological property of the slip layer. Figure 9 illustrates the components of the Sliper, test methods, and the process of pumping prediction. The pipe diameter of the Sliper is $126 \mathrm{~mm}$. The top surface of the piston has a pressure sensor installed, which measures the concrete's pressure and the pressure caused by the pipes at the same time. The pipe speed is measured using a distance transducer, which is related to the concrete's flow rate during pumping. Weights could be added to increase the pipe's slipping speed. The measured pipe speed and pressure are saved to generate a graph that illustrates the pressure-flow rate relationship, as shown on the bottom left image of Fig. 9. In the pressure-flow rate relation curve, the Y-intercept is directly related to the yield stress of the slip layer, and the slope is a function directly related to its viscosity. After measuring the rheological property of the slip layer through the Sliper test, the following equation could be used to predict the actual pumping (Mechtcherine et al. 2014).

$$
P=P_{y}+P_{v}+P_{H}=\frac{4 L}{D} a+\frac{16 \cdot L \cdot Q}{\pi \cdot D^{3}} b+\rho \cdot g \cdot H
$$

where $a=\tau_{i 0}$ is the equivalent of yield stress at the slip layer, $b=\mu_{i} / e$ is the equivalent of effective viscosity at the slip-layer, $Q$ is the flow rate, $D$ and $L$ are the diameter and length, respectively, of the pipe, $e$ is the thickness of the sliplayer, $\rho$ is the density of concrete, and $H$ is the pumping height. The rheological property of the slip layer, $a$ and $b$, could be derived through the Sliper test. A desired pressure could be calculated by applying a desired flow rate $Q$. The slip layer's thickness cannot be measured through the Sliper test. Thus, the viscosity $\left(\mu_{i}\right)$ and thickness $(e)$ of the slip layer cannot be calculated. However, since the concrete flow condition in the Sliper test is assumed to be the same as the flow condition in the actual pumping process, the slip layer's thickness is also assumed to be the same for both cases. Therefore, pumping can be predicted by calculating the parameter $b=\mu_{i} / e$ based on the pressure-flow rate relationship without the need of the precise slip layer thickness.

The method proposed by Mechtcherine et al. (2014) considers only the friction on the surface of the pipe's interior without concrete flow. In other words, it cannot examine the shear flow that occurs inside the concrete during the actual pumping process. Thus, this method is not suitable for predicting pumping for concrete mixtures with very low yield stress, such as highly flowable concrete.

Kim et al. (2014) developed a device to measure the internal frictional resistance. This device was installed in a $50 \mathrm{~m}$ horizontal pumping circuit to measure the frictional resistance of concrete mixture. Concrete pumping pressure was predicted based on the frictional resistance coefficient derived through the $50 \mathrm{~m}$ pumping test. The results showed that the predicted value and applied pressure value are highly correlated. Nevertheless, its application on predicting the pumpability of concrete is limited because it needs a fullscale pumping test.

\section{Factors Influencing the Concrete Pumpability}

\subsection{Coarse Aggregate Size}

Choi et al. (2014) evaluated the pumping performance of 6 concrete mixtures. Two nominal strengths of 24 and $50 \mathrm{MPa}$ were considered and the maximum coarse aggregate at each strength was 10,20 or $25 \mathrm{~mm}$. The dosage of superplasticizer was controlled to have the same slump flow of $600 \mathrm{~mm}$. Table 1 reports the rheological properties of the concrete and corresponding slip layer. Larger maximum coarse aggregate size increased the viscosity of the concrete and the slip layer. The high viscosity was required for the acceptable stability of large-sized aggregate concrete. The yield stress of the concrete and that of slip layer contrarily decreased as the maximum coarse aggregate size increased. High dosage of superplasticizer required for large-sized aggregate concrete results in decreasing the yield stress. In 

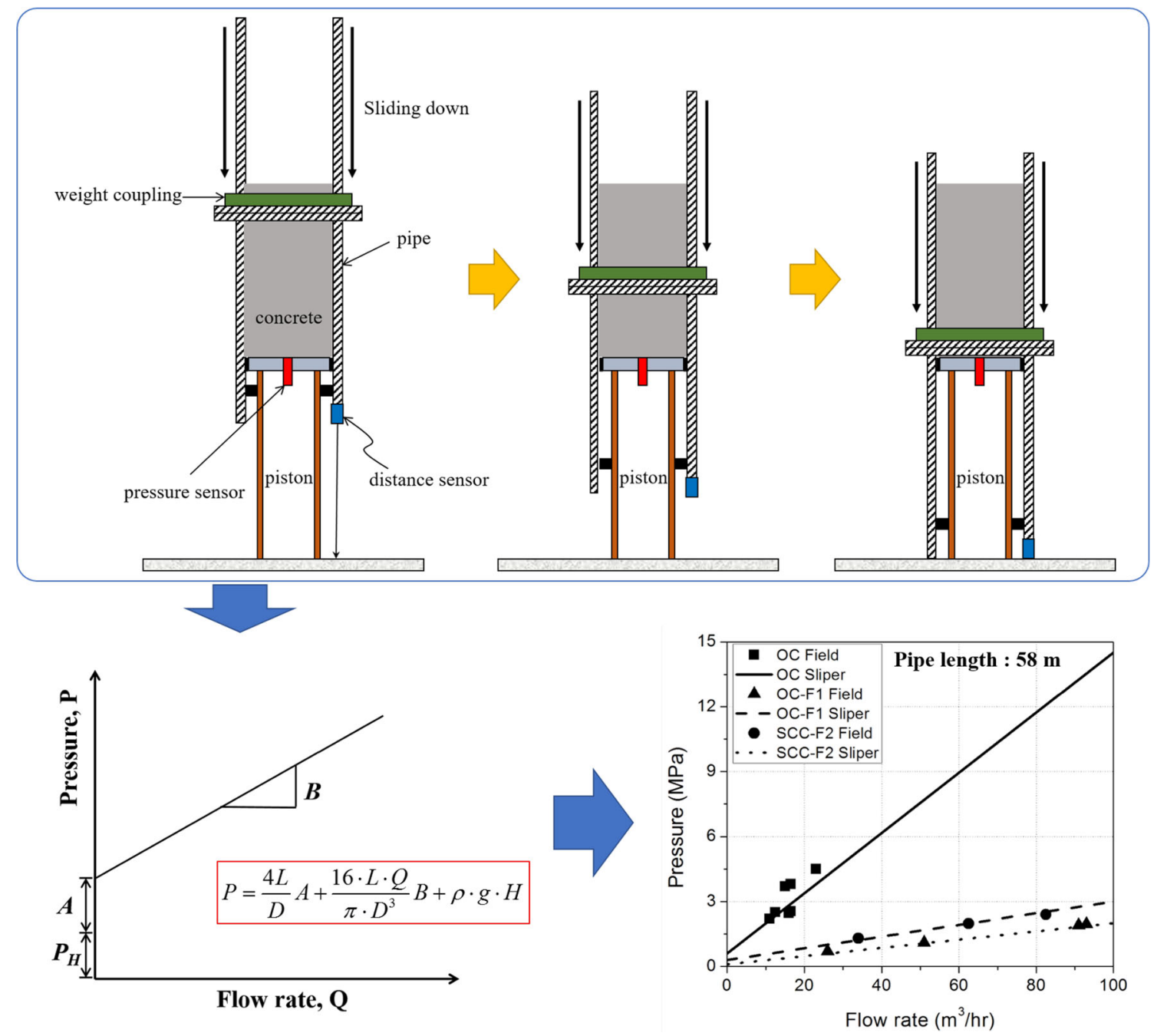

Fig. 9 Schematic constitution of Sliding Pipe Rheometer (Mechtcherine et al. 2014).

Table 1 Measured rheological properties of the concrete and the slip-layer (Choi et al. 2014).

\begin{tabular}{c|c|c|c|c|c}
\hline Design strength (MPa) & $\begin{array}{c}\text { Maximum aggregate } \\
\text { size (mm) }\end{array}$ & \multicolumn{2}{|c|}{ Concrete } & \multicolumn{2}{c}{ Slip-layer } \\
\cline { 2 - 6 } & 10 & Yield stress (Pa) & Viscosity (Pa s) & Yield stress (Pa) & Viscosity (Pa s) \\
\hline \hline \multirow{2}{*}{24} & 20 & 300.0 & 8.0 & 15.0 & 0.5 \\
\cline { 2 - 6 } & 25 & 200.0 & 10.0 & 12.0 & 0.8 \\
\cline { 2 - 6 } & 10 & 150.0 & 13.0 & 11.0 & 1.0 \\
\cline { 2 - 6 } & 20 & 100.0 & 25.0 & 10.0 & 2.0 \\
\cline { 2 - 6 } & 25 & 80.0 & 40.0 & 5.0 & 2.5 \\
\hline
\end{tabular}

order to examine the effects of coarse aggregate size on pumping performance, the pressure per unit length required for $30 \mathrm{~m}^{3} / \mathrm{h}$ pumping was calculated with the rheological measurements. Figure 10 compares the prediction results. S24 and S50 refer to the compressive strengths of 24 and $50 \mathrm{MPa}$, respectively, and A10, A20, and A25 refer to the maximum coarse aggregate sizes of 10,20 , and $25 \mathrm{~mm}$, respectively. The $25 \mathrm{~mm}$ mixture requires roughly twice the pressure compared to the $10 \mathrm{~mm}$ mixture. Therefore, it was concluded that the maximum coarse aggregate size has a significant influence on concrete pumping.

\subsection{Mineral Admixtures}

Jeong et al. (2016) conducted a test to measure the rheological properties of the concrete and the slip layer of highstrength concrete mixtures with varying types and amount of mineral admixture. The rheological measurements were again used to evaluate the pumping performance. Figure 11 


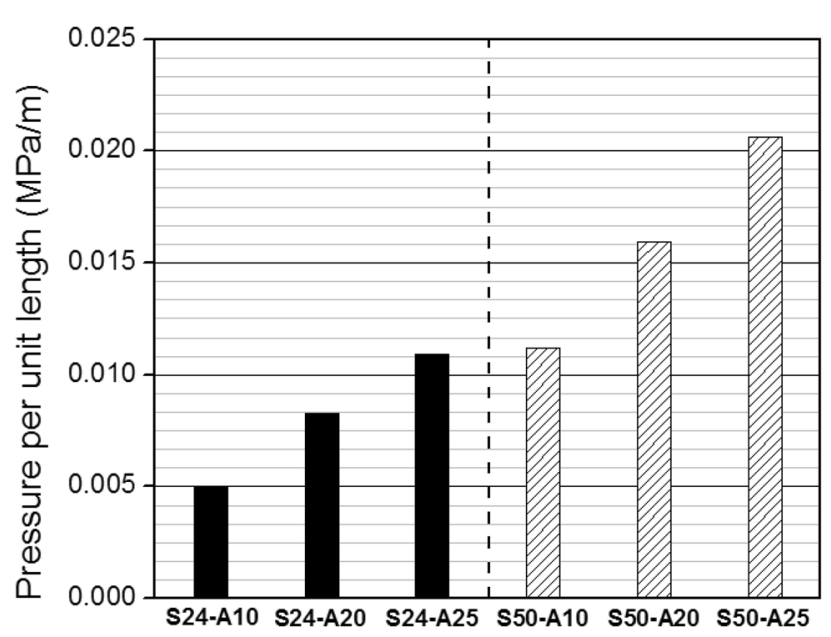

Fig. 10 Pressure per unit length required for $30 \mathrm{~m}^{3} / \mathrm{h}$ pumping (Choi et al. 2014). * $S$ is the compressive strength; $A$ is the maximum size of coarse aggregate.

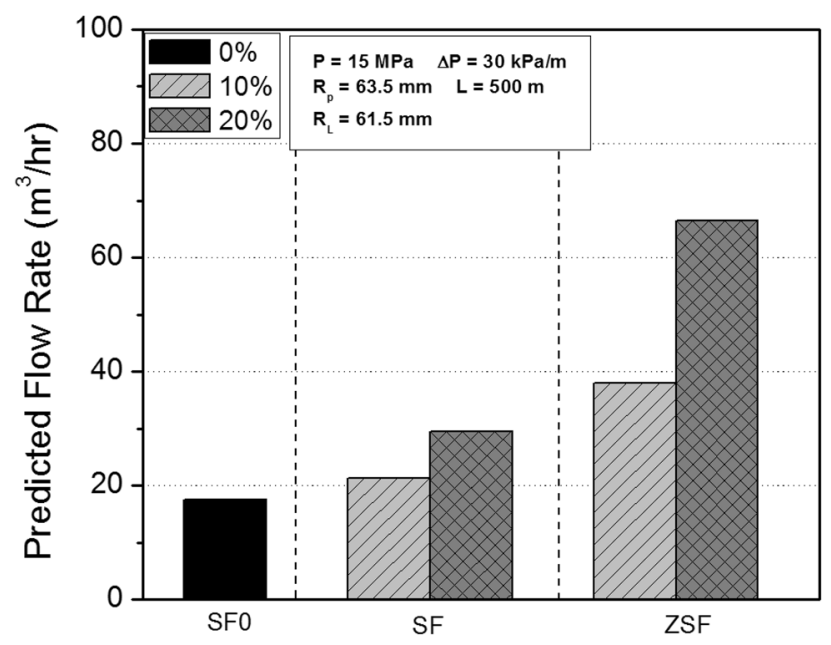

Fig. 11 Calculated flow rate for SF and ZSF test series (Jeong et al. 2016). *SF is the silica fume; ZSF is the zirconia silica fume.

illustrates the pumping performance evaluation results for the mixtures incorporating silica fume (SF) or zirconia silica fume (ZSF), where SF0 was a control mix having no mineral admixture. When each mix is pumped on $500 \mathrm{~m}$ by $15 \mathrm{MPa}$, the flow rate of pumped concrete increases by incorporating more amount of silica fume. The use of zirconia silica fume produces roughly twice as much flow rate compared to when using regular silica fume.

Figure 12 shows the effect of fly ash on the pumping performance, Where C8-FA0 is a control mix showing the strength of $80 \mathrm{MPa}$ with no fly ash incorporation. FA1 and FA2 refer to the different types of fly ash used in the mixture. Reviewing the example case of pumping performance evaluation, different tendencies were observed according to the type of fly ash. In the case of FA1 the pumping performance was proportional to the amount used in the mixture, but no such correlation was observed with FA2.

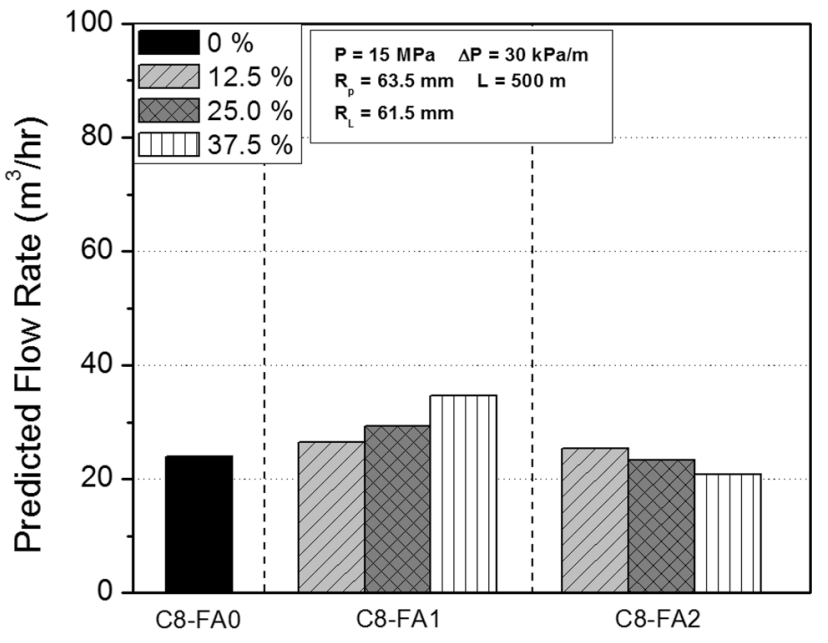

Fig. 12 Calculated flow rate for FA test series (Jeong et al. 2016). ${ }^{*} \mathrm{C} 8$ is the compressive strength ( $80 \mathrm{MPa}$ ); FA is the fly ash.

\subsection{Superplasticizer}

Jeong et al. (2016) examined the effects of the amount of superplasticizer on pumping performance. Table 2 reports the slump flow test results and rheological property measurements for 10 concrete mixtures of which compressive strength was 50,80 , or $100 \mathrm{MPa}$ and the dosage of superplasticizer varies according to the mixture. Regardless of the strength, the slump flow increases with a higher dosage of superplasticizer. In addition, the viscosity of the slip layer decreases with the higher dosage. The measurements of the rheological properties of the concrete and the slip layer were used for pumping prediction. Figure 13 illustrates the flow rate calculation results (Jeong et al. 2016). Under the same compressive strength, the flow rate was proportional to the dosage of superplasticizer even though its rate of change is different. Therefore, the pumping performance can be improved by adequately increasing the superplasticizer dosage.

\section{Discussion for Future Study}

The previously introduced research (Kaplan et al. 2005; Choi et al. 2013; Kwon et al. 2013a, 2013b; Mechtcherine et al. 2014; Choi 2013; Choi et al. 2014) allows to predict concrete pumping with a high level of accuracy. Nevertheless, still the research on topics of concrete pumping is required. It is very difficult to manage a consistent quality in the actual work field, and in the case of a concrete mixture that satisfies special requirements, namely, the cases that it needs to transport with concrete of low pumping performance. Special mixtures such as high-strength concrete and fiber-reinforced concrete are also asked to show acceptable pumping performance even when their slip layer is poorly developed. In such cases, the pipe may get clogged during the pumping process. Pipe clogging delays the construction, which results in economic damage. In addition to the difficulty in the construction process, cleaning out and reinstalling the pipes are time consuming and expensive task to be 
Table 2 Experimental results for SP test series (Jeong et al. 2016).

\begin{tabular}{|c|c|c|c|c|c|c|}
\hline \multirow{2}{*}{$\begin{array}{c}\text { Design strength } \\
(\mathrm{MPa})\end{array}$} & \multirow{2}{*}{$\begin{array}{c}\text { Dosage of } \\
\text { superplasticizer }(\%)\end{array}$} & \multicolumn{2}{|c|}{ Concrete } & \multicolumn{2}{|c|}{ Slip-layer } & \multirow[t]{2}{*}{ Slump flow $(\mathrm{mm})$} \\
\hline & & Yield stress $(\mathrm{Pa})$ & Viscosity (Pa s) & Yield stress $(\mathrm{Pa})$ & Viscosity (Pa s) & \\
\hline \multirow[t]{4}{*}{50} & 0.80 & 144 & 53.4 & 72.0 & 2.49 & 370 \\
\hline & 1.00 & 74.0 & 43.0 & 9.0 & 1.98 & 485 \\
\hline & 1.10 & 41.0 & 44.0 & 77.0 & 1.56 & 540 \\
\hline & 1.27 & 16.0 & 61.1 & 25.0 & 0.60 & 655 \\
\hline \multirow[t]{3}{*}{80} & 1.10 & 84.0 & 107 & 32.0 & 4.06 & 450 \\
\hline & 1.25 & 2.0 & 94.0 & 40.0 & 2.92 & 575 \\
\hline & 1.40 & 0.1 & 79.0 & 5.0 & 2.98 & 665 \\
\hline \multirow[t]{3}{*}{100} & 1.10 & 13.4 & 121 & 15.3 & 4.77 & 515 \\
\hline & 1.20 & 4.0 & 112 & 21.5 & 3.99 & 585 \\
\hline & 1.40 & 0.1 & 77.0 & 0.1 & 3.22 & 695 \\
\hline
\end{tabular}

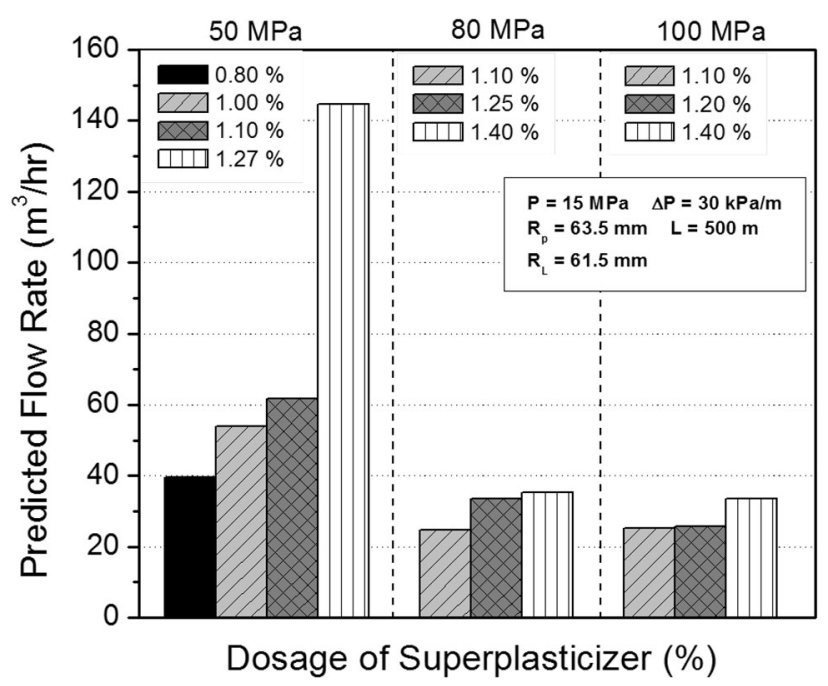

Fig. 13 Calculated flow rate for SP test series (Jeong et al. 2016).

done. Therefore, it is necessary to scientifically analyze the pipe clogging phenomenon, which includes evaluating segregation resistance or rheological property of concrete under a highpressure condition.

Another important area is concerning the procurement of slip layer in long distance pumping. The pumping test conducted by Choi (2013) proved that the slip layer is maintained up to $1000 \mathrm{~m}$. However, in these days concrete for tunnel lining is sometimes pumped up to $3 \mathrm{~km}$. Loss of slip layer is also possible because the rheological properties of concrete change during the pumping (Kwon et al. 2013) and the pumping pressure increases for the long-distance pumping. Quantitative evaluations on the long-distance pumping performance or examinations on the loss of slip layer have not yet been conducted. If the slip layer is dissipated, further research is required to prepare a countermeasures and develop a method to maintain the slip layer.

The tribometer to measure the property of the slip layer also needs to be more optimized. The final form proposed by Ngo et al. (2010) and Kwon et al. (2013) has inconvenience that the test requires two separate measurements to eliminate the shear rate concentration on the bottom edge of the cylinder. Analysing the torque measurement at different concrete heights is expected to characterize the duplicate measurement, which certainly needs multiple tests and simulations. Parameterizing the shear-stress field in the tribometer can allows a single measurement for evaluating the rheological property of the slip layer.

\section{Concluding Remarks}

Increase in the need of a quantitative pumping prediction have stimulated numerous researches on measuring the rheological properties of the slip layer and developing a model for the pumping prediction. The methods for measuring the rheological properties of the slip layer can be largely divided into two categories: the use of tribometer or pipe segment. A tribometer rotates a cylinder immersed in concrete, and then the rheological property of the slip layer is calculated with the torque and angular velocity measurement. The other method measured the internal pressure and velocity of a concrete-filling pipe.

The development of technologies capable of obtaining a quantitative estimation of concrete pumping allowed us to predict the flow rate based on given values of concrete mixture, pumping height or distance, and pumping pressure. Conversely, the pumping pressure and an adequate mixproportion can be derived based on given values of pumping height or distance and the target flow rate. In addition, the pumping model evaluated the effect of the maximum coarse aggregate size, the type and amounts of mineral admixture, and the dosage of superplasticizer on the pumpability of concrete. Concrete mixtures under the same compressive strength showed degradation of pumping performance as the maximum coarse aggregate size increased. Also, as a result of calculating the flow rate under the same pressure condition, $10 \mathrm{~mm}$ coarse aggregate size showed twice as much flow rate compared to the $25 \mathrm{~mm}$ coarse aggregate size. In 
regards to mineral admixtures, the type and amount of silica fume or fly ash were analyzed. Using silica fume enhanced the pumping performance, and particularly the pumping performance showed twice as much improvements when using zirconia silica fume compared to using regular silica fume. The effect of fly ash on the pumping performance depended on its type. The pumping performance showed improvements in all mixtures as the dosage of superplasticizer increased.

\section{Acknowledgments}

This research was supported by the General Individual Research in General Researcher Program through the National Research Foundation of Korea (NRF) funded by the Ministry of Education (Grant No. NRF2013R1A1A2013470).

\section{Open Access}

This article is distributed under the terms of the Creative Commons Attribution 4.0 International License (http://creativecommons.org/licenses/by/4.0/), which permits unrestricted use, distribution, and reproduction in any medium, provided you give appropriate credit to the original author(s) and the source, provide a link to the Creative Commons license, and indicate if changes were made.

\section{References}

Alekseev, S. N. (1952). On the calculation of resistance in pipe of concrete pumps. Mekhanizatia Storitel'stva, 9(1), 8-13.

Brookfield Engineering Laboratories Inc. (2006). More solutions to sticky problems. Brookfield, MA.

Browne, R. D., \& Bamforth, P. B. (1977). Tests to establish concrete pumpability. ACI Journal Proceedings, 74(5), 193-203.

Chalimo, T., Touloupov, N., \& Markovskiy, M. (1989). Peculiarities of concrete pumping. Minsk: Stroikniga. (in Russian).

Chapdelaine, F. (2007). Etude fondamentale et partique sur le pompage du beton. Ph. D. Thesis, Faculty of the Higher Studies of Laval University, Canada.

Choi, M. S. (2013). Prediction of concrete pumping performance base on the evaluation of lubrication layer properties. Ph. D. Thesis, Korea Advanced Institute of Science and Technology, Korea.

Choi, M. S., Kim, Y. J., Jang, K. P., \& Kwon, S. H. (2014). Effect of the coarse aggregate size on pipe flow of pumped concrete. Construction and Building Materials, 66, 723-730.

Choi, M. S., Kim, Y. J., \& Kwon, S. H. (2013a). Numerical prediction on pipe flow of pumped concrete based on shearinduced particle migration. Cement and Concrete Research, $52,216-224$.
Choi, M. S., Roussel, N., Kim, Y. J., \& Kim, J. K. (2013b). Lubrication layer properties during concrete pumping. Cement and Concrete Research, 45(3), 69-78.

De Larrard, F., Hu, C., Sedran, T., Szitkar, J. C., Joly, M., Claux, F., \& Derkx, F. (1997). A new rheometer for soft-to-fluid fresh concrete. ACI Materials Journal, 94(3), 234-243.

Ede, A. N. (1957). The resistance of concrete pumped through pipelines. Magazine of Concrete Research, 9(27), 129-140.

Feys, D., Khayat, K. H., \& Khatib, R. (2016). How do concrete rheology, tribology, flow rate and pipe radius influence pumping pressure? Cement and Concrete Research, 66, 38-46.

Feys, D., Khayat, K. H., Perez-Schell, A., \& Khatib, R. (2014). Development of a tribometer to characterize lubrication layer properties of self-consolidating concrete. Cement and Concrete Research, 54, 40-52.

Feys, D., Khayat, K. H., Perez-Schell, A., \& Khatib, R. (2015). Prediction of pumping pressure by means of new tribometer for highly-workable concrete. Cement and Concrete Research, 57, 102-115.

Jacobsen, S., Haugan, L., Hammer, T. A., \& Kalogiannidis, E. (2009). Flow conditions of fresh cortar and concrete in different pipes. Cement and Concrete Research, 39(11), 997-1006.

Jacobsen, S., Mork J. H., Lee, S. F., \& Haugan, L. (2008). Pumping of concrete and mortar-state of the Art. COIN Project Report, 5, 1-44.

Jeong, J. H., Jang, K. P., Park, C. K., Lee, S. H., \& Kwon, S. H. (2016). Effect of admixtures on pumpability for highstrength concrete. ACI Materials Journal, 113(3), 323-333.

Jo, S. D., Park, C. K., Jeong, J. H., Lee, S. H., \& Kwon, S. H. (2012). A computational approach to estimating a lubricating layer in concrete pumping. Computers Materials and Continua, 27(3), 189-210.

Kaplan, D., Larrard, F. D., \& Sedran, T. (2005a). Design of concrete pumping circuit. ACI Materials Journal, 102(2), 110-117.

Kaplan, D., Larrard, F. D., \& Sedran, T. (2005b). Avoidance of blockages in concrete pumping process. ACI Materials Journal, 102(3), 183-191.

Kim, H. R., Cho, H. K., Kim, J. C., \& Lee, K. C. (2014). Prediction of pumping friction resistance coefficient in pipe influenced by concrete rheology properties. Journal of the Korea Institute of Building Construction, 14(2), 18-126.

Koehler, E. P., Fowler, D. W., Ferraris, C. F., \& Amziane, S. (2006). A new portable rheometer for fresh self-consolidating concrete. In C. Shi \& K. H. Khayat (Eds.), Workability of SCC: Roles of its constituents and measurement techniques, SP-233 (pp. 97-116). Farmington Hills, MI: American Concrete Institute.

Kwon, S. H., Jo, S. D., Park, C. K., Jeong, J. H., \& Lee, S. H. (2013a). Prediction of concrete pumping: Part I-development of new tribometer for analysis of lubricating layer. ACI Materials Journal, 110(6), 647-656.

Kwon, S. H., Jo, S. D., Park, C. K., Jeong, J. H., \& Lee, S. H. (2013b). Prediction of concrete pumping: Part II-analytical prediction and experimental verification. ACI Materials Journal, 110(6), 657-668. 
Lipovetski, M. (1963). Concrete pumps and their use in dam construction (pp. 15-85). Moscow, Russia: Moskva-Leningrade. (in Russian).

Mechtcherine, V., Nerella, V. N., \& Kasten, K. (2014). Testing pumpability of concrete using sliding pipe rheometer. Construction and Building Materials, 53, 312-323.

Met-flow, S. A. (2002). Model UVP-duo with software version 3 user's guide. Switzerland: Met-flow Co.

Morinaga, S. (1973). Pumpability of concrete and pumping pressure in pipelines. Proceedings of a RILEM Seminar, Leeds, 3, 1-39.

Ngo, T. T., Kadri, E. H., Bennacer, R., \& Cussigh, F. (2010). Use of tribometer to estimate interface friction and concrete boundary layer composition during the fluid concrete pumping. Construction and Building Materials, 23(7), 1253-1261.

Phillips, R. J., Armstrong, R. C., \& Brown, R. A. (1992). A constitutive equation for concentrated suspensions that accounts for shear-induced particle migration. Physics of Fluids A, 4(1), 30-40.
Rio, O., Rodriguez, A., Nabulsi, S., \& Alvarez, M. (2005). Pumping quality control method based on online concrete pumping assessment. ACI Materials Journal, 102(2), $110-117$.

Sakuta, M., Kasanu, I., Yamane, S., \& Sakamoto, A. (1989). Pumpability of fresh concrete (pp. 125-133). Tokyo, Japan: Takenaka Technical Research Laboratory.

Tanigawa, Y., Mori, H., \& Noda, Y. (1991). Theoretical study on pumping of fresh concrete, Concrete Institute of Japan, Vol. 13.

Tattersall, G. H., \& Banfill, P. F. (1983). The rheology of fresh concrete (p. 356). London, UK: Pitman Advanced Publishing Program.

Wallevik, J. E. (2008). Minimizing end-effects in the coaxial cylinders viscometer: Viscoplastic flow inside the ConTec BML Viscometer 3. Journal of Non-Newtonian Fluid Mechanics, 155(3), 116-123.

Weber, R. (1968). The transport of concrete by pipeline. London, UK: Cement and Concrete Association. 